\title{
Molecular analysis of $W W O X$ expression correlation with proliferation and apoptosis in glioblastoma multiforme
}

\author{
Katarzyna Kosla • Elzbieta Pluciennik • Agata Kurzyk • \\ Dorota Jesionek-Kupnicka $\cdot$ Radzislaw Kordek • \\ Piotr Potemski • Andrzej K. Bednarek
}

Received: 21 November 2009/Accepted: 24 May 2010/Published online: 10 June 2010

(C) The Author(s) 2010. This article is published with open access at Springerlink.com

\begin{abstract}
Glioblastoma multiforme is the most common type of primary brain tumor in adults. WWOX is a tumor suppressor gene involved in carcinogenesis and cancer progression in many different neoplasms. Reduced WWOX expression is associated with more aggressive phenotype and poor patient outcome in several cancers. We investigated alternations of WWOX expression and its correlation with proliferation, apoptosis and signal trafficking in 67 glioblastoma multiforme specimens. Moreover, we examined the level of WWOX LOH and methylation status in WWOX promoter region. Our results suggest that loss of heterozygosity (relatively frequent in glioblastoma multiforme) along with promoter methylation may decrease the expression of this tumor suppressor gene. Our experiment revealed positive correlations between $W W O X$ and $B c l 2$ and between WWOX and Ki67. We also confirmed that WWOX is positively correlated with ErbB4 signaling pathway in glioblastoma multiforme.
\end{abstract}

Keywords WWOX ErbB 4 - Glioblastoma multiforme · Methylation $\cdot \mathrm{LOH}$

Katarzyna Kosla and Elzbieta Pluciennik are contributed equally.

K. Kosla $(\bowtie)$ E. Pluciennik · A. Kurzyk · A. K. Bednarek Department of Molecular Cancerogenesis, Medical University of Lodz, Mazowiecka St 6/8, 92-215 Lodz, Poland e-mail:kkosla@csk.umed.lodz.pl

D. Jesionek-Kupnicka $\cdot$ R. Kordek

Department of Chemotherapy, Medical University of Lodz, Paderewski St 4, 93-509 Lodz, Poland

P. Potemski

Department of Molecular Pathology and Neuropathology, Medical University of Lodz, Pomorska St 251, 92-216 Lodz, Poland

\section{Introduction}

Glioblastoma multiforme (GBM) is the most common type of primary brain tumor in adults. This highly lethal neoplasm is particularly difficult to treat due to its specific features, i.e., poor permeability of blood-brain barrier, that prevents chemotherapeutics from reaching their target, and low ability of brain tissue to renew, that makes surgical intervention very difficult and venturesome. The major molecular changes are well defined and differentiate GBM into primary and secondary tumor subtypes. The main known alterations are LOH 10q, EGFR amplification, p16 ${ }^{I N K 4 a}$ deletion, PTEN and $p 53$ mutations [1]. However, the molecular basis of brain tumorigenesis still requires further intensive study, since neoplastic transformation is a complicated process resulting from both genetic and epigenetic alterations of the genome.

The tumor suppressor gene WWOX is localized in a common fragile site FRA16D (locus 16q23.3-24.1). Protein encoded by $W W O X$ is an oxidoreductase containing two WW protein interaction domains. The biological role of the protein is not yet defined, although there are suppositions that it may play a part in steroid hormones metabolism and ErbB4 receptor signaling pathway [2, 3]. Modified expression of WWOX suppressor gene was observed in many types of tumors [4-6]. Absence of point mutations necessitates searching for other mechanisms which can deregulate WWOX expression. Loss of heterozygosity in WWOX locus was reported in many types of cancer (breast, esophagus, and lungs, among others [7-9]). Some authors observed a correlation between WWOX promoter methylation status and its expression level [10-13]. Promoter methylation is one of the key mechanisms silencing tumor suppressor genes. It has been well demonstrated that expression of genes such as $p 27[14,15]$, 
BRCAl [16, 17], and CDHI [18] is blocked by hypermethylation in some cancer types.

Futile traditional methods of glioblastoma multiforme treatment have provoked an intensive search for a better understanding of molecular aberrations underlying the formation and progression of this kind of cancer. The aim of our experiments was to elucidate the role of the WWOX suppressor gene in GBM. Here, we report on our investigation into correlations between expression of WWOX and genes involved in cellular functions such as proliferation (Ki67), signal transduction (EGFR, ErbB4), and apoptosis (Bax, Bcl2). Moreover, we assessed the methylation state of WWOX promoter and examined the association between methylation and expression level. Additionally, we evaluated frequency of loss of heterozygosity in WWOX locus and its influence on gene expression.

\section{Materials and methods}

\section{Patients}

The study included 67 cases of glioblastoma multiforme, diagnosed according to the World Health Organization criteria for classification of brain tumors. The group consisted of 20 females, 35 males and 2 not specified. The patients' mean age was 58.6 years (range 27-76). The mean follow-up was 11.8 months (range 1-26).

\section{Total RNA isolation, cDNA syntesis and DNA isolation}

RNA was extracted from frozen brain tissues, stored at $-80^{\circ} \mathrm{C}$ in RNAlater (Ambion), using TRIzol reagent (Invitrogen). cDNA synthesis was performed from $10 \mu \mathrm{g}$ of total RNA at volume of $100 \mu$ using ImProm RT-II ${ }^{\mathrm{TM}}$ reverse transcriptase (Promega). Reverse transcription was carried out under the following conditions: incubation at $25^{\circ} \mathrm{C}$ for $5 \mathrm{~min}$ and $42^{\circ} \mathrm{C}$ for $60 \mathrm{~min}$, heating at $70^{\circ} \mathrm{C}$ for 15 min. cDNA samples were diluted with sterile deionized water to a total volume of 150 and $2 \mu \mathrm{l}$ was added to a PCR reaction.

DNA was recovered from organic rests of TRIzol after RNA isolation using manufacturer's protocol.

Real-time RT-PCR analysis

Real-time RT-PCR was performed using Rotor-Gene ${ }^{\mathrm{TM}}$ 3000 (Corbett Research). PCR products were detected using SYBR ${ }^{\circledR}$ Green I and qPCR Core kit for SYBR ${ }^{\circledR}$ Green I (Eurogentec). All reactions were performed in duplicate. We analyzed relative expression level of 6 genes (Bax, Bcl2, EGFR, Ki67, WWOX, ErbB4 isoforms JM-a and $J M-b)$. The expression levels of investigated genes were normalized to three reference genes ( $R P S 17, H 3 F 3 A$, and $R P L P O)$.

Due to a relatively low level of WWOX mRNA, we used a semi-nested RT-PCR for detection of WWOX expression level. First, PCR reaction was performed with primers 5'-TGCAACATCCTCTTCTCCAACGAGCTGCAC- $3^{\prime}$ and $5^{\prime}$-TCCCTGTTGCATGGACTTGGTGAAAGGC- $3^{\prime}$ in $50 \mu \mathrm{l}$ reaction volume. Subsequently, $2 \mu$ of 200 -fold-diluted PCR product (171 bp) was used as a template for semi-nested PCR. The cycling protocol consists of: $2 \mathrm{~min}$ at $94^{\circ} \mathrm{C}, 30 \mathrm{~s}$ denaturation at $94^{\circ} \mathrm{C}, 30 \mathrm{~s}$ annealing at $63^{\circ} \mathrm{C}, 1 \mathrm{~min}$ extension at $72^{\circ} \mathrm{C}$ repeated for 77 cycles, and additional extension for $7 \mathrm{~min}$ at $72^{\circ} \mathrm{C}$.

Sequences of primers, annealing and detection temperatures, and the length of products are presented in Table 1.

Relative gene expression was calculated with the Roche guidebook according to a previously published algorithm [19]. Universal Human Reference RNA (Stratagene) composed of 10 cell lines was used as a calibrator.

All primers were designed to be intron-spanning to avoid amplification of genomic DNA. Detection temperature was determined above unspecific/primer-dimer melting temperature.

\section{$\mathrm{LOH}$ analysis}

Loss of heterozygosity detection was performed using "high" resolution melting of Rotor-Gene ${ }^{\mathrm{TM}} 3000$ (Corbett Research). Allelic losses were analyzed by PCR amplification with three sets of primers for microsatellites D16S518 (intron 1 of WWOX gene), D16S3096 and D16S504 (intron 8). The primer sequences were obtained from the Genome database. PCR cycling programs included 1 cycle with $95^{\circ} \mathrm{C}$ for $10 \mathrm{~min}$ followed by 35 cycles consisting of $94^{\circ} \mathrm{C}$ for $30 \mathrm{~s}, 56^{\circ} \mathrm{C}$ (for D16S3096 and D16S504) or $55^{\circ} \mathrm{C}$ (for D16S518) for $30 \mathrm{~s}, 72^{\circ} \mathrm{C}$ for $60 \mathrm{~s}$.

\section{MethylScreen}

To assess the level of promoter methylation we preformed the MethylScreen assay [20]. The method is based on a set of restriction digestions coupled with subsequent real-time PCR. DNA was isolated from frozen brain tumor tissue. Next, $2 \mu \mathrm{g}$ of DNA of every sample were divided into four 500-ng parts and each underwent different treatment. The first, called Mock, was a positive control, incubated with digestion buffer, yet without addition of any enzymes. The second was treated with two methylation-sensitive restriction enzymes (MSRE), HhaI and HpaII (cutting only unmethylated template). The third was incubated with methylation-dependent restriction enzyme (MDRE), $M c r B C$ (cutting only methylated DNA). The fourth, a negative control, was simultaneously double digested with 
Table 1 Real-time PCR reactions characteristics

\begin{tabular}{|c|c|c|c|}
\hline Gene primers $\left(5^{\prime} \rightarrow 3^{\prime}\right)$ & PCR product size (bp) & Annealing temp. $\left({ }^{\circ} \mathrm{C}\right)$ & Detection temp. $\left({ }^{\circ} \mathrm{C}\right)$ \\
\hline $\begin{array}{l}\text { H3F3A } \\
\text { AGGACTTTAAAAGATCTGCGCTTCCAGAG } \\
\text { ACCAGATAGGCCTCACTTGCCTCCTGC }\end{array}$ & 76 & 65 & 72 \\
\hline $\begin{array}{l}\text { RPLPO } \\
\text { ACGGATTACACCTTCCCACTTGCTAAAAGGTC } \\
\text { AGCCACAAAGGCAGATGGATCAGCCAAG }\end{array}$ & 69 & 65 & 72 \\
\hline $\begin{array}{l}\text { RPS17 } \\
\text { AAGCGCGTGTGCGAGGAGATCG } \\
\text { TCGCTTCATCAGATGCGTGACATAACCTG }\end{array}$ & 87 & 64 & 72 \\
\hline $\begin{array}{l}\text { Bcl2 } \\
\text { TTGGCCCCCGTTGCTTTTCCTC } \\
\text { TCCCACTCGTAGCCCCTCTGCGAC }\end{array}$ & 122 & 56 & 81 \\
\hline $\begin{array}{l}\text { Bax } \\
\text { AGAGGTCTTTTTCCGCGTGGCAGC } \\
\text { TTCTGATCAGTTCCGGCACCTTG }\end{array}$ & 137 & 56 & 81 \\
\hline $\begin{array}{l}\text { Ki67 } \\
\text { TCCTTTGGTGGGCACCTAAGACCTG } \\
\text { TGATGGTTGAGGCTGTTCCTTGATG }\end{array}$ & 156 & 56 & 81 \\
\hline $\begin{array}{l}\text { WWOX } \\
\text { GAGCTGCACCGTCGCCTCTCCCCAC } \\
\text { TCCCTGTTGCATGGACTTGGTGAAAGGC }\end{array}$ & 150 & 63 & 77 \\
\hline $\begin{array}{l}E G F R \\
\text { AGCTTCTTGCAGCGATACAGCTCAGAC } \\
\text { TGGGAACGGACTGGTTTATGTATTCAGG }\end{array}$ & 106 & 58 & 81 \\
\hline $\begin{array}{l}J M-a \text { ErbB4 } \\
\text { ACACAGCCCTCCTCCTGCCTACAC } \\
\text { AGGGCACAGACACTCCTTGTTCAGC }\end{array}$ & 95 & 56 & 76 \\
\hline $\begin{array}{l}J M-b \text { ErbB } 4 \\
\text { AGAGCAAGAATTGACTCGAATAGGAACC } \\
\text { AGGGCACAGACACTCCTTGTTCAGC }\end{array}$ & 82 & 56 & 76 \\
\hline
\end{tabular}

MSRE and MDRE enzymes. Each reaction consisted of equivalent amounts of $1 \times \mathrm{NEB}$ buffer 2 (10 mM Tris$\mathrm{HCl}, 55 \mathrm{mM} \mathrm{NaCl}, 10 \mathrm{mM} \mathrm{MgCl}{ }_{2}, 1 \mathrm{mM}$ DTT), $1 \mu \mathrm{g} / \mathrm{ml}$ bovine serum albumin (BSA), $2 \mathrm{mM}$ guanosine-5' $5^{\prime}$-triphosphate (GTP), water and appropriate enzymes. Digestions were incubated for $4 \mathrm{~h}$ at $37^{\circ} \mathrm{C}$ and then $20 \mathrm{~min}$ at $65^{\circ} \mathrm{C}$ to halt enzyme activity. Following enzyme digestion, samples were analyzed by real-time PCR using the RotorGene $3000^{\mathrm{TM}}$ system. Using locus-specific PCR primers, intact genomic DNA was amplified, while genomic DNA that had been cleaved by restriction endonucleases was not. A change in the number of amplifiable loci was detected in the fluorescence cycle threshold among the separate digests. Standard curve data was created for each patient by setting the Mock positive control as 100 standard and double digest negative control as 0.001 standard. The threshold was set by maximizing the regression fit to the standard curve. The DNA sample was scored as methylated if the difference between Mock and MSRE/MDRE digestions $\mathrm{Ct}$ was $>1$.

Two sets of PCR primers were designed for the amplification of two genomic DNA fragments at the promoter and first exon of the $W W O X$ gene. The PCR products were 384 and $413 \mathrm{bp}$ long and contained $\% \mathrm{GC}=66.5$. The forward primer sequence for the first $(-508$ to $-174 \mathrm{bp})$ region of the promoter was 5'-ACAGAAGCCCAGGACAACAGCAT GG-3', and the reverse primer sequence was 5'-ACCACGAAGCTGAAATCCAGTCTCCG-3' ${ }^{\prime}$. The forward primer sequence for the second region (from $-171 \mathrm{bp}$ to $+239 \mathrm{bp}$ ) was 5'-AGACTGGATTTCAGCTTCGTGGTCG-3', and the reverse primer sequence was 5'-AAGCTCCTTAACAGTTACTTTCACTTTGCAC- $3^{\prime}$.

For the $W W O X$ distal promoter fragment, the reaction mix consisted of $2.5 \mu$ l of SYBR ${ }^{\circledR}$ Green I, qPCR Core kit for $\mathrm{SYBR}^{\circledR}$ Green I reagents (Eurogentec), $10 \mathrm{nM}$ of each primer, $4 \mu \mathrm{l}$ of digested DNA template. Real-time PCR 
was conducted at the following conditions: $95^{\circ} \mathrm{C}$ for $5 \mathrm{~min}$, followed by 50 cycles at $94^{\circ} \mathrm{C}$ for $30 \mathrm{~s}, 55^{\circ} \mathrm{C}$ for $30 \mathrm{~s}$, and $72^{\circ} \mathrm{C}$ for $90 \mathrm{~s}$, and $77^{\circ} \mathrm{C}$ for $15 \mathrm{~s}$. Fluorescence reading was performed after each cycle at $77^{\circ} \mathrm{C}$. For the second $W W O X$ promoter fragment (covering the $3^{\prime}$ end of the promoter and part of exon 1), the reaction mix consisted of $2.5 \mu \mathrm{l}$ of SYBR $^{\circledR}$ Green I, qPCR Core kit for SYBR $^{\circledR}$ Green I reagents, $10 \mathrm{nM}$ of each primer, $4 \mu \mathrm{l}$ of digested DNA template, and $70 \mathrm{mM}$ of betaine. Real-time PCR was conducted at the following conditions: $95^{\circ} \mathrm{C}$ for $5 \mathrm{~min}$, followed by 50 cycles at $94^{\circ} \mathrm{C}$ for $30 \mathrm{~s}, 50^{\circ} \mathrm{C}$ for $30 \mathrm{~s}$, and $72^{\circ} \mathrm{C}$ for $90 \mathrm{~s}$, and $83^{\circ} \mathrm{C}$ for $15 \mathrm{~s}$. Fluorescence reading was performed after each cycle at $83^{\circ} \mathrm{C}$.

\section{Statistical analysis}

Correlation analysis between the expression levels of WWOX and other genes and clinical factors was performed using non-parametric Spearman Rank Correlation test. Differences between transcription level of WWOX gene in relation to its methylation status, $\mathrm{LOH}$ and patients' sex were estimated by Student's $t$ test. All results were recognized statistically significant at confidence level $>95 \%$ $(P<0.05)$.

\section{Results}

The methylation analysis of 61 GBM tissue samples revealed that the first, distal fragment of WWOX promoter was methylated in $18 \%$ (11 of 61) of cases, while the second, nearby TATA box in 15\% (9 of 61). Further analyses revealed that methylation state of the distal promoter region had no influence on WWOX expression. Hence, to clarify the presentation, it has been excluded from further consideration in the current report. The mean WWOX expression level in samples with methylated second promoter fragment was noticeably lower than in unmethylated (11.71 vs $21.93 ; P=0.15$ ), although this difference was not statistically significant in the AspinWelch mean test. The medians were 6.23 for methylated and 12.04 for unmethylated samples $(P=0.23)$. Despite the absence of statistical significance in the obtained results, there was a noticeable tendency of promoter methylation to lower WWOX gene expression.

We observed a relatively high percentage of $\mathrm{LOH}$ for two out of three analysed microsatellites. The level of hemizygosity was D16S3096 (38.5\%) and D16S504 $(54.5 \%)$ which is significantly higher than homozygosity observed in the population. The two microsatellites are located adjacent to the end of WWOX gene, in intron 8. The details of the LOH analysis are presented in Table 2. Statistical analysis revealed no correlation between $\mathrm{LOH}$ and reduction of WWOX expression. In D16S3096, mean WWOX expression was 18.84 for heterozygous samples and 24.91 for homozygous $(P=0.63)$. The medians were 12.81 and 8.97 , respectively $(P=0.58)$. For the D16S504 microsatellite marker, these values were: means 26.94 versus $15.25(P=0.24)$ and medians 9.78 versus 10.9 $(P=0.71)$.

We also analyzed the WWOX expression level concurrently with reference to promoter methylation and microsatellite markers state. This revealed a difference in WWOX expression in homo- and heterozygotes, which was not noticeable in the summary analysis without considering methylation state. The highest expression was demonstrated by unmethylated, heterozygous samples, while the lowest by methylated, homozygous samples. Loss of heterozygosity lowered expression levels in unmethylated samples (with the exception of D15S504). Promoter methylation considerably reduces $W W O X$ expression both in hetero- and homozygous cases. The details are presented in Table 3.

In an experiment on 67 patients with GBM, we noticed a positive correlation between expression level of WWOX suppressor gene and marker of proliferation Ki67 $\left(R_{\mathrm{S}}=0.5440 ; P<0.0001\right)$. Correlation analysis of WWOX gene expression level with apoptotic pathway revealed a positive association with antiapoptotic gene $B c l 2$ mRNA level $\left(R_{\mathrm{S}}=0.7092 ; P<0.0001\right)$ but not with proapoptotic Bax mRNA level and Bcl2/Bax ratio $(P>0.05)$. Furthermore, there was a positive correlation with transcription level of WWOX and JM- $a$ isoform of ErbB4. We did not find any statistically significant association between $W W O X$ and EGFR expression level $(P>0.05)$, or between $W W O X$ and $J M-b$ isoform of ErbB4 $(P>0.05)$. The analysis of expression correlation between WWOX and other investigated genes is presented in Table 4.

There was no correlation between WWOX expression and factors such as age, sex and time of survival.

\section{Discussion}

\section{$\mathrm{LOH}$}

Lowered expression level of the WWOX gene has been observed in many types of cancer [8, 9, 11, 12, 21-27]. Among other possibilities, the reason might be the loss of heterozygosity or epigenetic changes such as methylation of $\mathrm{CpG}$ islands in promoter region. Several researchers have revealed LOH of WWOX locus in gastric [21], pancreatic [12], esophageal [8] and lung [9] cancer. In our study on GBM, we noticed no LOH in WWOX intron 1 (observed hemizygosity and populational homozygosity were nearly the same) and relatively frequent incidence of 
Table 2 An analysis of $\mathrm{LOH}$ in $W W O X$ region

\begin{tabular}{|c|c|c|c|}
\hline & D16S518 (\%) & D16S3096 (\%) & D16S504 (\%) \\
\hline Observed hemizygosity in GBM & 18 & 38.5 & 54.5 \\
\hline Populational homozyogosity ${ }^{a}$ & 17 & 26 & 36.7 \\
\hline Predicted loss of heterozygosity & 1 & 12.5 & 19.8 \\
\hline
\end{tabular}

${ }^{a}$ From Genome database

Table 3 Median WWOX expression in $\mathrm{LOH}$ and promoter methylation status differing subgroups

\begin{tabular}{lcc}
\hline & D16S518 & D16S3096 \\
\hline Heterozygous, unmethylated & 12.69 & 13.17 \\
Heterozygous, methylated & 6.63 & 6.23 \\
Hemizygous, unmethylated & 7.32 & 9.37 \\
Hemizygous, methylated & 5.66 & 5.85 \\
\hline
\end{tabular}

The differences between the subgroups' median WWOX expression were statistically insignificant

Table 4 Spearman rank correlation between $W W O X$ expression level and other tumour related genes

\begin{tabular}{lll}
\hline Gene & $\begin{array}{l}\text { Correlation } \\
\text { coefficient } R_{\mathrm{s}}\end{array}$ & $P$ \\
\hline EGFR & 0.2413 & NS $(0.0611)$ \\
ErbB4 JM- $a$ & 0.7102 & $<0.0001$ \\
ErbB4 JM- $b$ & 0.2108 & NS $(0.1029)$ \\
Ki67 & 0.5440 & $<0.0001$ \\
Bax & 0.2301 & NS $(0.0745)$ \\
Bcl2 & 0.7092 & $<0.0001$ \\
Bcl2/Bax & 0.1995 & NS $(0.1442)$ \\
\hline
\end{tabular}

hemizygosity at intron 8 (38.5 and 54.5\%). Although we did not observe a correlation of LOH with WWOX expression level, adding data on promoter methylation state to our analysis allowed us to observe such a connection. That indicates that loss of heterozygosity concurrently with promoter methylation affects the expression of WWOX gene in glioblastoma multiforme.

Promoter methylation

Hypermethylation of gene regulatory regions is a common event in cancer cells. In most cases, promoter methylation reduces or completely silences affected gene expression. WWOX promoter methylation has been reported to be a possible cause of reducing WWOX expression in breast, lung, bladder, pancreas and prostate cancers $[10,12,13]$. As shown in our experiment, methylation of the WWOX promoter region in the examined GBM samples was infrequent: $18 \%$ for the distal and $15 \%$ for the nearby TATA box promoter fragment. If it occurred, methylation slightly correlated with reduction of WWOX mRNA level, although the difference in mean expression for methylated and unmethylated samples was not statistically significant, probably because of the small number of methylated samples (11 and 9 of 61). Nevertheless, a tendency of WWOX promoter methylation to reduce its expression can be seen.

\section{Expression correlations}

Numerous authors have shown significant dependence of recurrence and drug resistance on alterations of the apoptosis pathway in glioma tumors. In patients with GBM, upregulation of antiapoptotic genes $B c l 2, B c l-x l, M C L-1$ and down-regulation of proapoptotic Bax gene were associated with recurrence of the disease [28]. Other authors have demonstrated that increasing the Bcl2 protein level correlates with higher grading in the glioma tumor cell line [29]. Moreover, up-regulation of antiapoptotic $B c l-x l$ gene with concurrent overexpression of EGFRVIII can be a cause of resistance to cisplatin agent [30]. Usage of $B c l 2$ specific antisense oligonucleotides activates apoptosis and may be helpful in treatment [31]. In our study, we found a positive correlation between expression of WWOX and the antiapoptotic gene $B c l 2$. However, we did not observe any connection of WWOX expression either with proapoptotic Bax gene expression or with a $B c l 2 / B a x$ ratio. These results are consistent with previously reported breast cancer analysis [32]. Interestingly, in vitro experiments conducted on MDA-MB-231 breast cancer cell line showed elevated apoptosis immediately after transfection with vectors harboring WWOX cDNA [33], though the stable transfectants showed elevated $B c l 2$ expression level, induced migration in Matrigel, and invasion through basal membrane, but inhibition of anchorage-independent growth [34]. Ovarian cancer cell lines showed similar behavior when transfected with WWOX cDNA; apoptosis was induced in cells growing in suspension but not in adherent cells [35].

Additionally, we found that WWOX expression was positively correlated with Ki67 mRNA level, considered as a marker of cell proliferation. A similar correlation of WWOX and Ki67 was observed in breast cancer samples [32]. Analysis of proliferation in ovarian cancer cell lines transfected with WWOX cDNA showed no correlation of 
WWOX and Ki67 [35]. There are reports presenting results of experiments which have proved that there is no association between Ki67 and factors such as age, Karnofsky index, and survival in human glioblastoma. However, there is a positive correlation with $p 53$ expression [36, 37]. There was no connection observed between proliferation activity in cells of anaplastic glioma with other molecular proliferation markers such as $p 16, R b, E G F R$ [37]. Nevertheless, Ki67 exhibited statistically significant differences in staining between the tumor types of astrocytoma, anaplastic astrocytoma, and glioblastoma [38]. The prognostic value of Ki67 in glioblastoma multiforme is currently strongly controversial [36, 39].

Unfortunately, we have less than $50 \%$ patient survival, tumor size and localization data, and therefore we were unable to perform reliable survival analysis.

\section{WWOX involvement in ErbB4 signalling pathways}

Two ErbB4 splice isoforms differ in a short juxtamembrane sequence. JM-a form is prone to sequential proteolytic cleavage conducted by tumor necrosis factor $\alpha$ converting enzyme (TACE) and $\gamma$-secretase. That intramembranous proteolysis releases intracellular domain (ICD) which might be translocated to the nucleus, where it transactivates genes expression [40]. As was shown by Aqeilan et al., ErbB4 might be regulated by the WWOX tumor suppressor protein [2, 41]. The WWOX-ErbB4 interaction occurs with both full-length membraneanchored ErbB4 and cleaved ICD fragment. When associated to uncleaved ErbB4, WWOX stabilizes the receptor in cellular membrane. Linked with ICD, WWOX prevents it from reaching the nucleus. The YAP protein has an opposite effect on ICD function. It facilitates ICD translocation to the nucleus and gene activation. Probably, YAP and WWOX compete for association with ICD fragment [41]. JM-b splice variant of ErbB4 harbors changes in a short sequence containing the cleavage site and is resistant to proteolytic enzymes activity. There is no evidence of WWOX association with JM-b. Our results showed a functional difference between JM-a and JM-b isoforms. While JM-a expression strongly correlated with WWOX ( $R=0.7102)$, which is consistent with breast cancer results obtained by Aqueilan et al. [2], JM-b did not show such a correlation. As shown elsewhere [41], WWOX associates with two PP $x$ Y motifs of JM-a by its first WW domain. Subcellular localization of transcription cofactors is one of the major ways to regulate gene expression activation. Our study confirmed that $W W O X$ is an important player in the ErbB4 signaling pathway although details of its action still wait to be revealed. The mechanism of the WWOX tumor suppressor function is not explained, but it seems that interactions with ErbB4 receptor might be one element.

\section{Conclusion}

Our study indicated that genomic deletions in the $3^{\prime}$ end of the WWOX gene occurs with high frequency in glioblastoma multiforme. $\mathrm{LOH}$ correlates with reduction of WWOX expression. Although without statistical confirmation, our results suggest that promoter methylation may also differentiate expression of WWOX. Moreover, WWOX transcription in GBM is strongly associated with proliferation and apoptosis, and is involved in a signal transduction through the ErbB4 pathway. WWOX genetic alternations and expression correlation with other cancer-related genes in GMB are similar to those observed in breast and ovarian cancer. Therefore, $W W O X$ gene inactivation seems to play an important role in GBM carcinogenesis.

Acknowledgments The authors would like to thank Ewa Latkowska for her excellent technical support. This study was funded by the Polish Ministry of Science and Higher Education grant N N401 233934 and Medical University of Lodz grant 502-19-840.

Open Access This article is distributed under the terms of the Creative Commons Attribution Noncommercial License which permits any noncommercial use, distribution, and reproduction in any medium, provided the original author(s) and source are credited.

\section{References}

1. Ohgaki H, Kleihues P (2007) Genetic pathways to primary, secondary glioblastoma. Am J Pathol 170:1445-1453

2. Aqeilan RI, Donati V, Gaudio E, Nicoloso MS, Sundvall M, Korhonen A et al (2007) Association of Wwox with ErbB4 in breast cancer. Cancer Res 67:9330-9336

3. Aqeilan RI, Hagan JP, BA De, Rawahneh M, Salah Z, Gaudio E et al (2009) Targeted ablation of the WW domain-containing oxidoreductase tumor suppressor leads to impaired steroidogenesis. Endocrinology 150:1530-1535

4. Aqeilan RI, Croce CM (2007) WWOX in biological control, tumorigenesis. J Cell Physiol 212:307-310

5. Hezova R, Ehrmann J, Kolar Z (2007) WWOX a new potential tumor suppressor gene. Biomed Pap Med Fac Univ Palacky Olomouc Czech Repub 151:11-15

6. Iliopoulos D, Guler G, Han SY, Druck T, Ottey M, McCorkell KA et al (2006) Roles of FHIT and WWOX fragile genes in cancer. Cancer Lett 232:27-36

7. Chen T, Sahin A, Aldaz CM (1996) Deletion map of chromosome $16 \mathrm{q}$ in ductal carcinoma in situ of the breast: refining a putative tumor suppressor gene region. Cancer Res 56:5605-5609

8. Kuroki T, Trapasso F, Shiraishi T, Alder H, Mimori K, Mori M et al (2002) Genetic alterations of the tumor suppressor gene WWOX in esophageal squamous cell carcinoma. Cancer Res 62:2258-2260

9. Yendamuri S, Kuroki T, Trapasso F, Henry AC, Dumon KR, Huebner K et al (2003) WW domain containing oxidoreductase 
gene expression is altered in non-small cell lung cancer. Cancer Res 63:878-881

10. Iliopoulos D, Guler G, Han SY, Johnston D, Druck T, McCorkell KA et al (2005) Fragile genes as biomarkers: epigenetic control of WWOX, FHIT in lung, breast, bladder cancer. Oncogene 24:1625-1633

11. Ishii H, Vecchione A, Furukawa Y, Sutheesophon K, Han SY, Druck $T$ et al (2003) Expression of FRA16D/WWOX and FRA3B/FHIT genes in hematopoietic malignancies. Mol Cancer Res 1:940-947

12. Kuroki T, Yendamuri S, Trapasso F, Matsuyama A, Aqeilan RI, Alder $\mathrm{H}$ et al (2004) The tumor suppressor gene WWOX at FRA16D is involved in pancreatic carcinogenesis. Clin Cancer Res 10:2459-2465

13. Qin HR, Iliopoulos D, Semba S, Fabbri M, Druck T, Volinia S et al (2006) A role for the WWOX gene in prostate cancer. Cancer Res 66:6477-6481

14. Lei PP, Zhang ZJ, Shen LJ, Li JY, Zou Q, Zhang HX (2005) Expression and hypermethylation of p27 kip1 in hepatocarcinogenesis. World J Gastroenterol 11:4587-4591

15. Qian X, Jin L, Kulig E, Lloyd RV (1998) DNA methylation regulates p27kip1 expression in rodent pituitary cell lines. Am J Pathol 153:1475-1482

16. Chan KY, Ozcelik H, Cheung AN, Ngan HY, Khoo US (2002) Epigenetic factors controlling the BRCA1 and BRCA2 genes in sporadic ovarian cancer. Cancer Res 62:4151-4156

17. Staff S, Isola J, Tanner M (2003) Haplo-insufficiency of BRCA1 in sporadic breast cancer. Cancer Res 63:4978-4983

18. Caldeira JR, Prando EC, Quevedo FC, Neto FA, Rainho CA, Rogatto SR (2006) CDH1 promoter hypermethylation and E-cadherin protein expression in infiltrating breast cancer. BMC Cancer 6:48-49

19. Pfaffl MW, Horgan GW, Dempfle L (2002) Relative expression software tool (REST) for group-wise comparison and statistical analysis of relative expression results in real-time PCR. Nucleic Acids Res 30:e36

20. Holemon H, Korshunova Y, Ordway JM, Bedell JA, Citek RW, Lakey N et al (2007) MethylScreen: DNA methylation density monitoring using quantitative PCR. Biotechniques 43:683-693

21. Aqeilan RI, Kuroki T, Pekarsky Y, Albagha O, Trapasso F, Baffa $\mathrm{R}$ et al (2004) Loss of WWOX expression in gastric carcinoma. Clin Cancer Res 10:3053-3058

22. Driouch K, Prydz H, Monese R, Johansen H, Lidereau R, Frengen E (2002) Alternative transcripts of the candidate tumor suppressor gene, WWOX, are expressed at high levels in human breast tumors. Oncogene 21:1832-1840

23. Gourley C, Paige AJ, Taylor KJ, Scott D, Francis NJ, Rush R et al (2005) WWOX mRNA expression profile in epithelial ovarian cancer supports the role of WWOX variant 1 as a tumour suppressor, although the role of variant 4 remains unclear. Int J Oncol 26:1681-1689

24. Guler G, Uner A, Guler N, Han SY, Iliopoulos D, Hauck WW et al (2004) The fragile genes FHIT and WWOX are inactivated coordinately in invasive breast carcinoma. Cancer 100: $1605-1614$

25. Ishii H, Furukawa Y (2004) Alterations of common chromosome fragile sites in hematopoietic malignancies. Int J Hematol 79: 238-242

26. Paige AJ, Taylor KJ, Taylor C, Hillier SG, Farrington S, Scott D et al (2001) WWOX: a candidate tumor suppressor gene involved in multiple tumor types. Proc Natl Acad Sci USA 98: $11417-11422$
27. Sbrana I, Veroni F, Nieri M, Puliti A, Barale R (2006) Chromosomal fragile sites FRA3B and FRA16D show correlated expression and association with failure of apoptosis in lymphocytes from patients with thyroid cancer genes. Chromosom Cancer 45:429-436

28. Strik H, Deininger M, Streffer J, Grote E, Wickboldt J, Dichgans $\mathrm{J}$ et al (1999) BCL-2 family protein expression in initial and recurrent glioblastomas: modulation by radiochemotherapy. $\mathrm{J}$ Neurol Neurosurg Psychiatry 67:763-768

29. Weller M, Malipiero U, Aguzzi A, Reed JC, Fontana A (1995) Protooncogene bcl-2 gene transfer abrogates Fas/APO-1 antibody-mediated apoptosis of human malignant glioma cells and confers resistance to chemotherapeutic drugs and therapeutic irradiation. J Clin Invest 95:2633-2643

30. Nagane M, Levitzki A, Gazit A, Cavenee WK, Huang HJ (1998) Drug resistance of human glioblastoma cells conferred by a tumor-specific mutant epidermal growth factor receptor through modulation of Bcl-XL and caspase-3-like proteases. Proc Natl Acad Sci USA 95:5724-5729

31. Julien T, Frankel B, Longo S, Kyle M, Gibson S, Shillitoe E et al (2000) Antisense-mediated inhibition of the bcl-2 gene induces apoptosis in human malignant glioma. Surg Neurol 53:360-368

32. Pluciennik E, Kusinska R, Potemski P, Kubiak R, Kordek R, Bednarek AK (2006) WWOX-the FRA16D cancer gene: expression correlation with breast cancer progression and prognosis. Eur J Surg Oncol 32:153-157

33. Iliopoulos D, Fabbri M, Druck T, Qin HR, Han SY, Huebner K (2007) Inhibition of breast cancer cell growth in vitro and in vivo: effect of restoration of Wwox expression. Clin Cancer Res $13: 268-274$

34. Lewandowska U, Zelazowski M, Seta K, Byczewska M, Pluciennik E, Bednarek AK (2009) WWOX, the tumour suppressor gene affected in multiple cancers. J Physiol Pharmacol 60(Suppl 1):47-56

35. Gourley C, Paige AJ, Taylor KJ, Ward C, Kuske B, Zhang J et al (2009) WWOX gene expression abolishes ovarian cancer tumorigenicity in vivo and decreases attachment to fibronectin via integrin alpha3. Cancer Res 69:4835-4842

36. Bouvier-Labit C, Chinot O, Ochi C, Gambarelli D, Dufour H, Figarella-Branger D (1998) Prognostic significance of Ki67, p53 and epidermal growth factor receptor immunostaining in human glioblastomas. Neuropathol Appl Neurobiol 24:381-388

37. Tortosa A, Vinolas N, Villa S, Verger E, Gil JM, Brell $\mathrm{M}$ et al (2003) Prognostic implication of clinical, radiologic, and pathologic features in patients with anaplastic gliomas. Cancer 97:1063-1071

38. Raghavan R, Steart PV, Weller RO (1990) Cell proliferation patterns in the diagnosis of astrocytomas, anaplastic astrocytomas and glioblastoma multiforme: a Ki-67 study. Neuropathol Appl Neurobiol 16:123-133

39. Torp SH (2002) Diagnostic and prognostic role of Ki67 immunostaining in human astrocytomas using four different antibodies. Clin Neuropathol 21:252-257

40. Jones FE (2008) HER4 intracellular domain (4ICD) activity in the developing mammary gland and breast cancer. J Mammary Gland Biol Neoplasia 13:247-258

41. Aqeilan RI, Donati V, Palamarchuk A, Trapasso F, Kaou M, Pekarsky Y et al (2005) WW domain-containing proteins, WWOX and YAP, compete for interaction with ErbB-4 and modulate its transcriptional function. Cancer Res 65:6764-6772 